\title{
Type 2 diabetes and impaired glucose tolerance in European children and adolescents with obesity - a problem that is no longer restricted to minority groups
}

\author{
Susanna Wiegand, Ursula Maikowski, Oliver Blankenstein, Heike Biebermann, Patrick Tarnow and \\ Annette Grüters \\ Paediatric Endocrinology, Charité Children's Hospital, Humboldt University of Berlin, Augustenburger Platz 1, 13353 Berlin, Germany \\ (Correspondence should be addressed to S Wiegand; Email: susanna.wiegand@charite.de)
}

\begin{abstract}
Background: The incidence of childhood obesity and type 2 diabetes is an increasing problem in Europe. We determined the prevalence of impaired glucose regulation in a predominantly Caucasian cohort of 491 children and adolescents with obesity.

Methods: Fasting glucose and insulin levels were determined in all 491 subjects. Patients with an abnormal fasting glucose or with additional risk factors (positive family history of type 2 diabetes, acanthosis nigricans, hyperlipidemia; $n=102$ ) underwent an oral glucose tolerance test (OGTT; $1.75 \mathrm{~g}$ glucose $/ \mathrm{kg}$ body weight). Homeostasis model assessment was used to estimate insulin resistance in all subjects. The insulin sensitivity index was determined in those subjects who underwent an OGTT. Screening for mutations in the melanocortin 4 receptor (MC4R) gene and the coding region of the brain-derived neutrophic factor (BDNF) in 37 patients with an impaired glucose tolerance was performed by WAVE analysis.

Results: Out of the total of 491 patients, 12 had an abnormal fasting glucose level. Of the 102 patients who underwent an OGTT, 37 had impaired glucose tolerance; 6 out of the 102 patients were diagnosed with type 2 diabetes. Eighty-eight per cent of patients with abnormal glucose tolerance and $66 \%$ of patients with type 2 diabetes were Caucasian. Insulin resistance indices correlated well with the degree of abnormal glucose tolerance. Using the screening algorithm for type 2 diabetes as advocated by the American Diabetes Association, $68 \%$ of patients with impaired glucose tolerance and $66 \%$ of patients with type 2 diabetes would have been missed. No abnormalities in the MC4R and BDNF genes were detected.

Conclusions: Impaired glucose tolerance and type 2 diabetes are far more common in obese European children of Caucasian origin than previously thought. Using fasting glucose levels as the main screening tool appears to be insufficient in detecting these children.
\end{abstract}

European Journal of Endocrinology 151 199-206

\section{Introduction}

Childhood obesity has reached epidemic proportions and is present not only in the United States but also worldwide (1). The prevalence of childhood obesity has more than doubled during the last two decades (2) in many regions of the world. Approximately 22 million children under 5 years of age are overweight (3). In the multiethnic population of Berlin, in 1985, $3 \%$ of pre-school children were defined as obese; in 2001 this figure was 13\% (4).

This epidemic of childhood obesity is associated with an increasing number of children and adolescents with type 2 diabetes (5), originally reported predominantly in ethnic groups with a high basic risk for type 2 diabetes (6). These data were confirmed in multiethnic groups in the United States and Italy $(7,8)$. The first reports of type 2 diabetes in obese white children in Great Britain were published recently (9).

In adults, the progression from normal to impaired glucose tolerance and to type 2 diabetes is caused by insulin resistance followed by decreased $\beta$-cell insulin secreting capacity. Impaired glucose tolerance is a risk factors for cardiovascular disease $(10,11)$. Recently it has been shown that with changes in lifestyle the progression from impaired glucose tolerance to type 2 diabetes can be prevented or delayed (12).

Severe obesity in childhood is a major risk factor in the pathogenesis of type 2 diabetes, but it is not yet clear which other clinical, biochemical or genetic factors determine manifestation. Therefore we investigated the prevalence of type 2 diabetes, impaired glucose tolerance and cardiovascular risk factors in a multiethnic European cohort of severely obese children and 
adolescents. Based on these results we critically analyzed the recommended screening methods for the diagnosis of impaired glucose regulation.

To date, mutations in the melanocortin 4 receptor (MC4R) gene are the most frequent molecular cause of obesity with mutations detected in 3-5\% of extremely obese patients studied (13). It was reported that patients carrying a MC4R mutation were euglycemic but have significantly elevated insulin levels compared with obese patients without an MC4R mutation (13). Recently it was shown in heterozygous knock-out mice of brain-derived neutrophic factor (BDNF) that BDNF acts downstream of MC4R signalling (14, 15). Heterozygous deletion of BDNF caused obesity due to hyperphagia, as well as highly elevated insulin and glucose levels in these mice (16). Therefore one may assume that mutations in the MC4R gene and probably also in the BDNF gene might represent risk factors for type 2 diabetes in childhood obesity. To start a genetic screening for predisposition for type 2 diabetes, a mutation screening by WAVE analysis was conducted in those children identified as being affected by impaired glucose tolerance and type 2 diabetes.

\section{Methods}

\section{Study population}

Between 2000 and 2002 we examined a cohort of 491 obese children and adolescents (aged 7-18 years) of multiethnic European origin for endocrine and metabolic abnormalities. Patients with obesity syndromes and other illnesses were excluded from this study. All 491 patients underwent a standard baseline diagnostic procedure including high-density lipoprotein (HDL)and low-density lipoprotein (LDL)-cholesterol, total cholesterol and triglyceride levels, as well as baseline levels of tri-iodothyronine (T3), thyroxine (T4) and thyroid-stimulating hormone (TSH).

We selected a high-risk group from this cohort according to the criteria of the American Diabetes Association (ADA) for type 2 diabetes screening in children and adolescents (17). The ADA recommends that children and adolescents should be tested for type 2 diabetes if they are obese and display at least one other risk factor, such as a positive family history of type 2 diabetes, signs of insulin resistance (acanthosis nigricans, dyslipidemia, hypertension, polycystic ovary syndrome) or an ethnic predisposition (17).

These criteria were met by 51 boys and 51 girls (Table 1) who underwent a 2-h oral glucose tolerance test (OGTT). None of the other patients had an impaired fasting glucose or elevated glycated hemoglobin (HbA1c) levels.

Body weight was measured with a digital scale (Soehnle, Germany) to the nearest $0.1 \mathrm{~kg}$ and height was measured with a wall-mounted stadiometer (Keller, Germany). The body mass index (BMI) was
Table 1 Clinical characteristics according to sex and age group.

\begin{tabular}{lcc}
\hline Characteristics & Male $(n=51)$ & Female $(n=51)$ \\
\hline Age (years) & $12 \pm 0.4$ & $12 \pm 0.5$ \\
Range (years) & $6-17$ & $6-17$ \\
BMI (kg/m $\left.{ }^{2}\right)$ & $33.3 \pm 0.9$ & $34.2 \pm 0.9$ \\
SDS-BMl & $2.68 \pm 0.07$ & $3 \pm 0.08$ \\
Ethnic group $(n)$ & 45 & 46 \\
Caucasian & 6 & 5 \\
Non-Caucasian & & \\
\hline
\end{tabular}

BMI, body mass index; SDS, standard deviation score; values are means \pm S.E.

calculated (the weight in kilograms divided by the square of the height in metres). All subjects had a BMI over the 97th percentile for age and sex and were thus classified as obese. The degree of obesity was quantified using Cole's least mean square method, which normalizes the BMI skewed distribution and expresses BMI as a standard deviation score (SDS-BMI) $(18,19)$.

Blood pressure was measured in a supine position after $5 \mathrm{~min}$ rest to the nearest $2 \mathrm{mmHg}$ using a Dinamap model and results were interpreted using percentiles for age and sex (20). Pubertal status was assessed according to the criteria of Tanner $(21,22)$.

None of the subjects were taking any medications.

\section{Oral glucose tolerance test (OGTT)}

The 102 subjects selected because of a high risk for type 2 diabetes followed a diet consisting of at least $250 \mathrm{~g}$ of carbohydrates per day for 3 days before the study.

After a 12-h overnight fast, these subjects underwent an OGTT at $0800 \mathrm{~h}$. Baseline samples were obtained for measurement of fasting (venous) glucose, fasting insulin, testosterone, thyroid hormones and lipids. Glucose was given orally $(1.75 \mathrm{~g} / \mathrm{kg}$ body weight, up to a maximum of $75 \mathrm{~g}$ glucose). Blood samples were drawn after 30, 60, 90 and $120 \mathrm{~min}$. Glucose and insulin concentrations were determined, and categorized using World Health Organization criteria (23).

Impaired fasting glucose was defined as a fasting plasma glucose of $110-125 \mathrm{mg} / \mathrm{dl}(6.1-6.9 \mathrm{mmol} / \mathrm{l}$; equivalent to $100-109 \mathrm{mg} / \mathrm{dl}$ in venous whole blood). Impaired glucose tolerance was defined as a 2-h plasma glucose level of 140-199 mg/dl (equals 120$179 \mathrm{mg} / \mathrm{dl}$ in venous whole blood); type 2 diabetes was defined as a fasting glucose level of $126 \mathrm{mg} / \mathrm{dl}$ $(7 \mathrm{mmol} / \mathrm{l}$; equivalent to $110 \mathrm{mg} / \mathrm{dl}$ in venous whole blood) or higher or a 2-h plasma glucose level of $200 \mathrm{mg} / \mathrm{dl}(11 \mathrm{mmol} ; 180 \mathrm{mg} / \mathrm{dl}$ in venous whole blood) or higher (24).

\section{Biochemical analysis}

Glucose was measured by the glucose oxidase method on venous whole blood immediately deproteinized with perchloric acid. The values obtained were transformed 
into plasma glucose values in order to calculate the insulin resistance index (homeostasis model assessment (HOMA)) and the insulin sensitivity index (ISI) by adding $10 \%$ to the venous whole blood glucose level. The lipid levels were determined by an enzymatic colorimetric test (analyser 704/717 Roche-Hitachi). The thyroid hormones and testosterone were measured with a fluoroimmunoassay (AutoDELFIA, PerkinElmer, Turku, Finland).

Insulin was measured with a radioimmunoassay (Pharmacia). The cross-reactivity with C-peptide was $<0.18 \%$ and with proinsulin, $41 \%$. The intra-assay variation was $5.8 \%$ for insulin and the inter-assay variation was $7 \%$.

\section{Calculations}

Two approaches were used to characterize insulin sensitivity. In the first approach, the HOMA for insulin resistance index (HOMA-IR) (25) was estimated using the formula:

$$
\begin{aligned}
\text { HOMA-IR }= & {[\text { fasting insulin }(\mathrm{mIU} / \mathrm{l})} \\
& \times \text { fasting glucose }(\mathrm{mmol} / \mathrm{l})] / 22.5
\end{aligned}
$$

Lower insulin resistance values indicate a higher insulin sensitivity, whereas higher values indicate a lower insulin sensitivity. The insulin resistance index correlates well with measures of insulin resistance obtained with the use of the euglycemic-hyperinsulinemicclamp technique, both from obese and non-obese children (7) and adults $(25,26)$.

In the second approach, insulin sensitivity was determined by the ISI of Matsuda \& De Fronzo (27).

$$
\begin{aligned}
\text { ISI }= & 10000 / \sqrt{ }[\text { fasting glucose }(\mathrm{mmol} / \mathrm{l}) \\
& \times \text { fasting insulin }(\mathrm{mIU} / \mathrm{l})] \\
& \times[\text { mean glucose }(\mathrm{mmol} / \mathrm{l}) \\
& \times \text { mean insulin }(\mathrm{mIU} / \mathrm{l}) \text { during OGTT] }
\end{aligned}
$$

$\beta$-Cell function was determined by the insulinogenic index (28), expressed as the ratio of the increment in the insulin level to that in the glucose level during the first $30 \mathrm{~min}$ after the ingestion of glucose. In children and adolescents, the insulinogenic index correlates well with the early insulin response obtained during a hyperglycemic-clamp study (7). A low insulinogenic index predicts the development of diabetes in adults $(29,30)$.

\section{Statistical analysis}

All values are expressed as means \pm S.E. Differences in the means of variables were tested using both parametric and non-parametric tests depending on the distribution of the variables.

The OGTT data were analysed using repeated measures ANOVA. Time was treated as a repeated measures factor, and normal/pathological glucose tolerance was used as a between-subjects factor. Correlation analyses were conducted using Spearman or Pearson correlation coefficients depending once again on the distribution of the variables. A probability value of less than 0.05 was considered significant. SPSS version 11 (SPSS, Chicago, IL, USA) was used for analysis.

The Ethics committee of the Humboldt University of Berlin approved the study. Written informed consent was obtained from the parents and the subjects.

\section{Genetic studies}

Genomic DNA was prepared from peripheral white blood cells using a commercial kit (Blood amp kit, Qiagen).

For mutational screening with the denaturating high-power liquid chromatography (HPLC) method (WAVE) (Transgenomics, Hannover), the coding region of the MC4R gene was amplified in four overlapping fragments with a maximum length of $350 \mathrm{bp}$. As a control we use a wild-type MC4R DNA sample that was verified by sequencing. In addition we used samples with known MC4R mutations (X35X for fragment 1, D90N for fragment 2, C271R for fragments 3 and 4).

The coding region of BDNF was amplified in two overlapping fragments and was analyzed by WAVE.

For WAVE analysis all PCR fragments and controls were screened with two temperatures. The entire coding region of the MC4R gene was amplified in one fragment and sequenced in three overlapping fragments using the BigDye Terminator Cycle Sequencing Ready Reaction Kit (Perkin Elmer, Weiterstadt, Germany) and an automatic sequencer (ABI 3100, Applied Biosystems, Foster City, CA, USA). A known polymorphism in fragment 1 (Val66Met) of the BDNF was examined by restriction enzyme analysis with PmlI. Digested PCR fragments were separated on a $2 \%$ agarose gel.

\section{Results}

\section{Prevalence of impaired glucose tolerance and type 2 diabetes}

Within the high-risk group $(n=102), 36.3 \%$ of the children and adolescents $(n=37)$ had an impaired glucose tolerance in OGTTs (Table 2$)$. In $5.9 \%(n=6)$ type 2 diabetes was diagnosed. Among the children and adolescents with impaired glucose tolerance, $86 \%$ $(n=32)$ were Caucasian and $14 \%(n=5)$ were noncaucasian; 4 Caucasian adolescents and 2 non-Caucasian adolescents had type 2 diabetes. No significant ethnic differences were found, either between Caucasian and non-Caucasian children or within the non-Caucasian group. 
Table 2 Clinical and metabolic phenotype of obese children and adolescents with normal glucose tolerance, impaired glucose tolerance or type 2 diabetes.

\begin{tabular}{|c|c|c|c|c|}
\hline & $\begin{array}{l}\text { Normal glucose tolerance } \\
\qquad(n=59)\end{array}$ & $\begin{array}{l}\text { Impaired glucose tolerance } \\
\qquad(n=37)\end{array}$ & $P$ value & $\begin{array}{l}\text { Type } 2 \text { diabetes } \\
\qquad(n=6)\end{array}$ \\
\hline \multicolumn{5}{|l|}{$\operatorname{Sex}(n)$} \\
\hline Male & 32 & 16 & & 3 \\
\hline Female & 27 & 21 & & 3 \\
\hline Age (years) & $12 \pm 0.4$ & $13 \pm 0.5$ & & $14 \pm 1.5$ \\
\hline Caucasian $(n)$ & 54 & 32 & & 4 \\
\hline Non-Caucasian (n) & 5 & 5 & & 2 \\
\hline BMI $\left(\mathrm{kg} / \mathrm{m}^{2}\right)$ & $32.4 \pm 0.8$ & $34.0 \pm 0.9$ & $P=0.05$ & $35.9 \pm 1.9$ \\
\hline SDS-BMI & $2.8 \pm 0.1$ & $2.9 \pm 0.1$ & $P=0.46$ & $2.9 \pm 0.2$ \\
\hline Insulin resistance index & $4.2 \pm 0.4$ & $6.4 \pm 0.5$ & $P<0.001^{*}$ & $7.6 \pm 1.7$ \\
\hline Insulin sensitivity index & $3.5 \pm 0.3$ & $1.9 \pm 0.1$ & $P<0.001^{*}$ & $1.2 \pm 0.1$ \\
\hline Insulinogenic index & $2.4 \pm 0.3$ & $4.6 \pm 2.5$ & $P=0.6$ & $2.1 \pm 0.5$ \\
\hline Fasting insulin level (mIU/l) & $19.6 \pm 1.6$ & $28.7 \pm 2.1$ & $P<0.001^{*}$ & $29.9 \pm 6.9$ \\
\hline Cholesterol (mg/dl) & $177 \pm 5.3$ & $181 \pm 5.4$ & $P=0.4$ & $170 \pm 16.6$ \\
\hline Triglycerides (mg/dl) & $126 \pm 9.6$ & $170 \pm 16.5$ & $P=0.01^{*}$ & $139 \pm 22.2$ \\
\hline HDL-cholesterol (mg/dl) & $45 \pm 1.4$ & $41 \pm 1.5$ & $P=0.1$ & $42 \pm 4.2$ \\
\hline LDL-cholesterol (mg/dl) & $109 \pm 5.4$ & $108 \pm 4.5$ & $P=0.6$ & $100 \pm 14.1$ \\
\hline
\end{tabular}

Values are means \pm S.E. All $P$ values are noted for the comparison with the group with normal glucose tolerance.

The insulin resistance index was determined by HOMA and is calculated as the product of the fasting insulin level (in mIU/I) and the fasting glucose level (in $\mathrm{mmol} / \mathrm{l}$ ), divided by 22.5 .

\section{Glucose and insulin responses to an oral glucose challenge}

Results of the OGTT in 102 children and adolescents are summarized for insulin and blood glucose in Fig. 1. Insulin and glucose values changed significantly over time $(P<0.0001)$.

Fasting insulin levels (Table 2) were higher in children and adolescents with impaired glucose tolerance or diabetes than in subjects with normal glucose tolerance. Furthermore, the insulin response to an oral glucose charge was elevated in children and adolescents with impaired glucose tolerance as compared with the responses in those with normal glucose tolerance.

The fasting blood glucose levels (Fig. 1) were higher in children and adolescents with impaired glucose tolerance $(90.3 \pm 1.2 \mathrm{mg} / \mathrm{dl})$ than in those with normal glucose tolerance $(86.6 \pm 0.7 \mathrm{mg} / \mathrm{dl})(P=0.02)$. Similarly, at $120 \mathrm{~min}$, glucose levels were higher in children and adolescents with impaired glucose tolerance $(124.7 \pm 1.7 \mathrm{mg} / \mathrm{dl})$ than in those with normal glucose tolerance $(97.6 \pm 1.7 \mathrm{mg} / \mathrm{dl})(P<0.001)$.

The six patients with type 2 diabetes showed heterogeneous insulin and glucose levels with a large standard deviation due to different stages of $\beta$-cell failure.

\section{Early-phase insulin secretion}

There were no significant differences in the early changes in the insulin level (within $30 \mathrm{~min}$ ), glucose level or the insulinogenic index (Fig. 2) between children and adolescents with normal and impaired glucose tolerance. In contrast, subjects with type 2 diabetes showed a significantly greater increase in the glucose level at $30 \mathrm{~min}$ (Fig. 1) compared with those
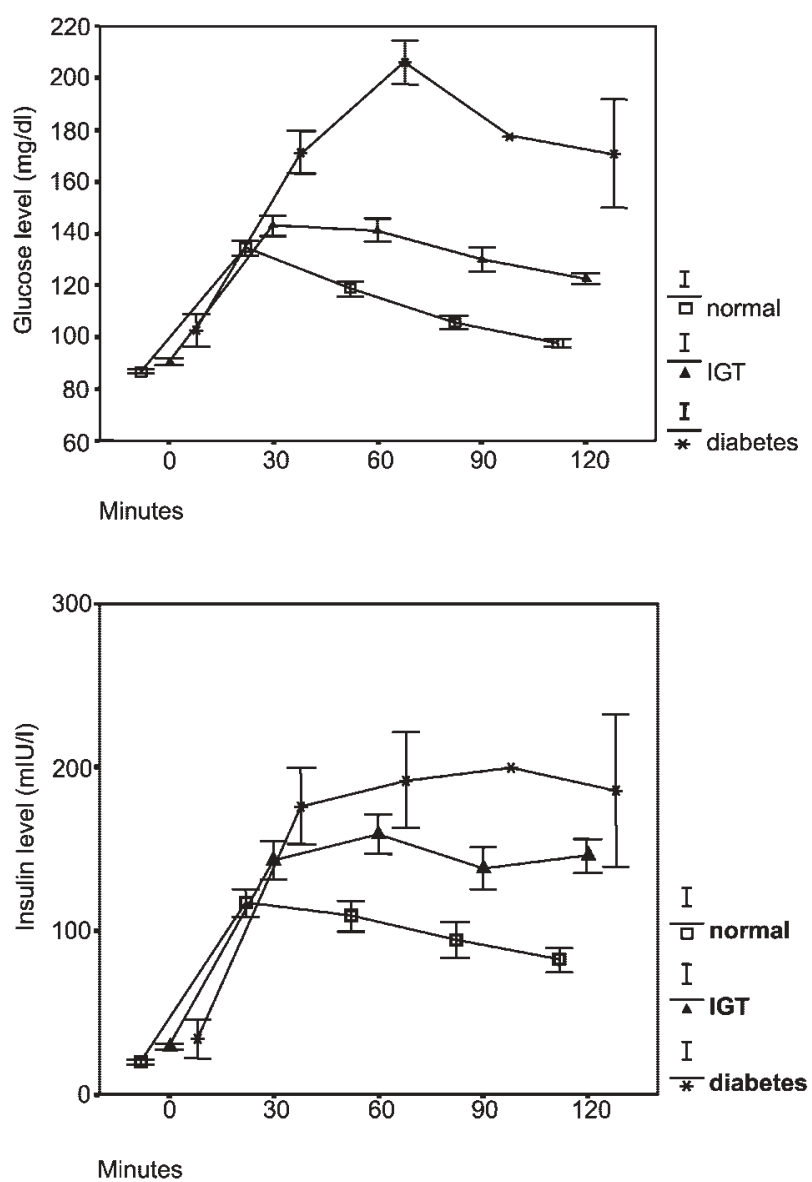

Figure 1 Mean \pm S.E. glucose and insulin responses during the OGTT in children and adolescents with normal glucose tolerance, impaired glucose tolerance and type 2 diabetes mellitus (glucose values are in $\mathrm{mg} / \mathrm{dl}$, to convert to $\mathrm{mmol} / \mathrm{l}$ multiply by 0.05551 ). 
that occurred in subjects either with impaired glucose tolerance $(P=0.05)$ or normal glucose tolerance $(P=0.01)$. However, this increase in the glucose level at $30 \mathrm{~min}$ was not associated with a significant increase in insulin levels. This indicates a remaining secretion capacity of the $\beta$-cells. Consequently, the calculated insulinogenic index (Fig. 2) was higher in the impaired glucose tolerance group and slightly but not significantly lower than that among subjects with normal glucose tolerance and type 2 diabetes $(P=0.6)$.

Fasting glucose level versus 2-h glucose level: comparison of WHO and American diagnostic criteria

The ADA encourages the use of fasting glucose rather than the OGTT for the diagnosis of diabetes and impaired glucose regulation (31). The WHO, however, recommends the OGTT as a screening procedure (24).

The differences in diagnostic criteria led to different results regarding prevalence rates $(\kappa=0.34)$. In this study far more subjects were identified as having an impaired glucose regulation using WHO criteria compared with ADA criteria. Four patients with type 2 diabetes would have been missed if only fasting blood glucose had been employed as the diagnostic criterion (Table 3). The $\kappa$ values underline the lack of agreement between ADA and WHO criteria.

\section{Risk factors associated with insulin resistance and insulin sensitivity}

The correlation between HOMA-IR and ISI was $r=-0.93(P<0.0001)$. Both measures were strongly correlated with fasting insulin, with $r=0.98$

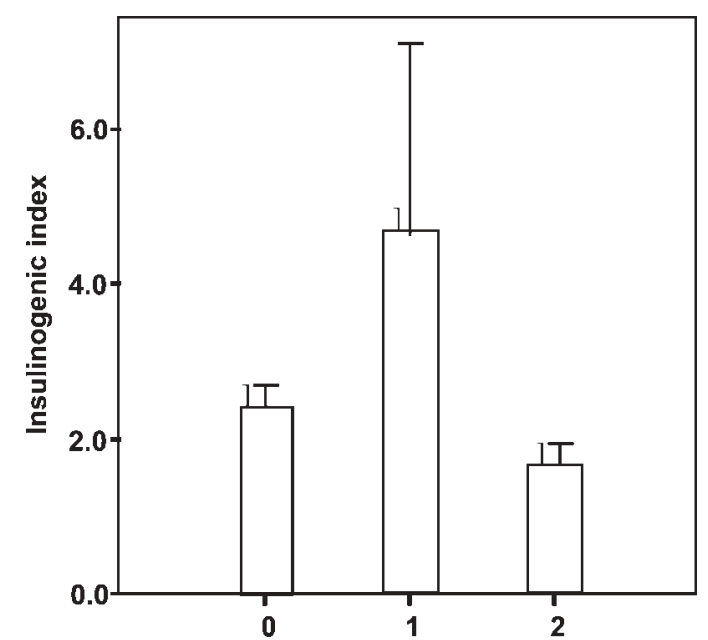

Figure 2 Mean \pm S.E. of the change in insulin to the change in glucose (insulinogenic index) in obese children and adolescents with normal glucose tolerance $(0)$, impaired glucose tolerance (1) or diabetes mellitus (2).
Table 3 Comparison of criteria for the diagnosis of impaired glucose regulation according to ADA and $\mathrm{WHO}$.

\begin{tabular}{lll}
\hline & ADA criteria & WHO criteria \\
\hline Impaired fasting glucose & $n=12$ & $n=12$ \\
Impaired glucose tolerance & & $n=37$ \\
Type 2 diabetes mellitus & $n=2$ & $n=6$ \\
Normal glucose regulation & $n=88$ & $n=59$ \\
Total & $n=102$ & $n=102$ \\
\hline
\end{tabular}

$\kappa=0.34$ (no significant agreement between WHO and ADA criteria).

$(P<0.0001)$ and $r=-0.9(P<0.0001)$ for HOMAIR and ISI respectively. Both HOMA-IR and ISI were also correlated with the 2-h glucose level, with $r=0.44(P<0.0001)$ for HOMA-IR and $r=-0.55$ $(P<0.0001)$ for ISI.

In addition HOMA-IR, ISI and fasting insulin were correlated to cardiovascular risk factors (Table 4).

Nonparametric tests were used to compare differences in the means of HOMA-IR and ISI between different groups of children and adolescents.

Puberty The study population was divided into a prepubertal group (Tanner stage I) and a group approaching or at puberty (Tanner stages II-V). Children at Tanner stage I $(n=29)$ showed significantly lower values for HOMA-IR and higher values for ISI compared with children and adolescents at Tanner stages $\mathrm{II}-\mathrm{V}(P=0.002$ and $P=0.007)$ (Fig. 3).

Sex There were no significant differences between girls and boys concerning insulin resistance or insulin sensitivity. However, girls with increased levels of total testosterone showed significantly higher values for HOMA-IR and lower values for ISI compared with girls with normal hormone levels $(P=0.039$ and $P=0.045)$ (data not shown).

Acanthosis nigricans The study population was divided into a group with and without acanthosis nigricans. Children and adolescents with this condition showed significantly higher values for HOMA-IR and lower values for ISI $(P=0.001$ and $P<0.001)$.

Ethnic origin Caucasian and non-Caucasian subjects showed similar HOMA-IR and ISI.

\section{Insulin resistance syndrome}

We evaluated the degree to which children and adolescents show early risk factors for diabetes type 2, described as the insulin resistance syndrome (32).

In our study population of 102 obese children and adolescents, 4 showed all the signs of the insulin resistance syndrome, i.e. insulin resistance, hypertension, dyslipoproteinemia and increased uric acid. In $80 \%$ of the children and adolescents at least two of these signs were present. 
Table 4 Correlations of cardiovascular risk factors with insulin resistance, insulin sensitivity and fasting insulin levels $(n=102)$.

\begin{tabular}{|c|c|c|c|c|c|}
\hline Variable & Mean & S.E. & $\begin{array}{c}\text { Correlation } r \text { with } \\
\text { HOMA }\end{array}$ & $\begin{array}{c}\text { Correlation } \boldsymbol{r} \\
\text { with ISI }\end{array}$ & $\begin{array}{l}\text { Correlation } r \text { with } \\
\text { fasting insulin }\end{array}$ \\
\hline Total cholesterol (mg/dl) & 178.7 & 3.75 & 0.1 & -0.1 & 0.1 \\
\hline LDL-cholesterol (mg/dl) & 108.5 & 3.66 & 0.02 & -0.1 & 0.01 \\
\hline HDL-cholesterol (mg/dl) & 43.3 & 1.0 & $-0.3(*)$ & $0.3^{\star *}$ & $-0.2\left(^{*}\right)$ \\
\hline Triglycerides (mg/dl) & 143.8 & 8.6 & $0.3^{\star \star}$ & $-0.4^{\star \star}$ & $0.33^{* *}$ \\
\hline Uric acid $(\mathrm{mg} / \mathrm{dl})$ & 5.6 & 0.1 & $0.3(* *)$ & $-0.3(*)$ & $0.3(* *)$ \\
\hline Systolic blood pressure $(\mathrm{mmHg})$ & 124 & 1.3 & $0.2\left(^{*}\right)^{\prime}$ & $-0.2^{*}$ & 0.2 \\
\hline Diastolic blood pressure (mmHg) & 69.6 & 0.9 & 0.14 & -0.12 & 0.009 \\
\hline SDS-BMI & 2.84 & 0.6 & 0.14 & -0.1 & $0.3^{\star *}$ \\
\hline
\end{tabular}

Table shows Spearman correlations of HOMA, ISI and fasting insulin with fasting total cholesterol, LDL-cholesterol, HDL-cholesterol, triglycerides, uric acid, systolic and diastolic blood pressure and SDS-BMI. *Significant correlation $(P<0.05)$, ${ }^{*}$ significant correlation $(P<0.01),\left({ }^{*}\right)$ after partial correlation with $\mathrm{BMI}$ as a confounding variable: no more significant. All results were checked by partial correlation with BMI as a confounding variable according to spurious correlation.

Forty-three of the obese children and adolescents suffered from an impaired glucose regulation (37 with impaired glucose tolerance and 6 with type 2 diabetes). This group was analyzed separately: in 27 of these subjects $(63 \%)$ other signs of the insulin resistance syndrome, such as hyperlipidemia, hypertension or elevated uric acid were present.

Triglycerides were significantly higher and HDLcholesterol lower among the children and adolescents with impaired glucose tolerance and diabetes than among those with normal glucose tolerance (Table 2). No differences in systolic and diastolic blood pressure were observed between children and adolescents between the two groups.

\section{Analysis of the MC4R and BDNF gene}

From 37 of the patients with impaired glucose tolerance, analysis of the MC4R and BDNF genes was performed by the WAVE method. No abnormalities were observed in either the MC4R gene or the BDNF gene.

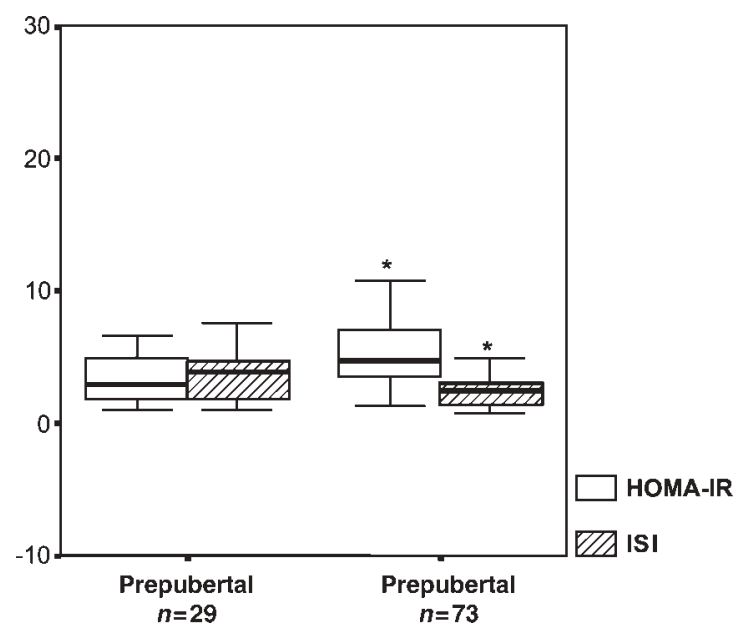

Figure 3 Median ( \pm 1 and 3 quartile) of HOMA-IR and ISI.
Sequencing of 10 patients was performed to control the results obtained with the WAVE method. Screening for the polymorphism Val66Met in the BDNF gene resulted in 2 patients homozygous for Met66 (5\%), 8 patients were heterozygous $(21.6 \%)$ and 28 were homozygous wild-type Val66 (73\%).

\section{Discussion}

From a large number of children and adolescents $(N=491)$ with obesity attending the outpatient department we selected a high-risk group according to the ADA criteria $(N=102)$ for diabetes screening. This high-risk group underwent an OGTT to determine the prevalence and influencing factors of impaired glucose regulation. We chose the OGTT as an extended screening method, as previous studies have shown that the fasting glucose level is an insensitive method for detecting impaired glucose regulation (33). In a recent study, Sinha et al. (7) found a very low prevalence of impaired fasting glucose in obese children and adolescents with impaired glucose tolerance (less than $0.08 \%$ ) (7).

The results of our study strongly confirm these findings. The fasting glucose level detected only $32 \%$ of the subjects with an impaired glucose tolerance and only $33 \%$ of the patients with diabetes who were identified by the OGTT.

In the group of obese multiethnic children and adolescents with a risk factor for type 2 diabetes reported in this study, a high prevalence of impaired glucose tolerance was found. The frequency of impaired glucose tolerance in a recent study of obese American children and adolescents from a multiethnic background is slightly lower (25\% compared with $37 \%$ in our study population), but these patients were not selected because of a high risk for type 2 diabetes (7). Type 2 diabetes was diagnosed in six patients. Four of these were of Caucasian and two of non-Caucasian origin. All had a positive family history for type 2 diabetes. In contrast the four adolescents with type 2 diabetes described by Sinha et al. (7) belonged to ethnic risk 
groups for type 2 diabetes: two black Americans and two Hispanic Americans.

Recently European authors have reported that lower prevalence rates of impaired glucose tolerance and no type 2 diabetes have been identified in a large cross-sectional Italian study of 710 European obese children and adolescents (4.5\%) (8). Only four cases of type 2 diabetes in white obese European children have been described (9). For economic and ethical reasons, in this study only the 102 patients at risk of type 2 diabetes underwent an OGTT, while the remaining 389 patients received a fasting glucose screening (34). This indicates that type 2 diabetes in adolescents is an emerging problem in Europe not only in ethnic minority groups (35) but also in multiethnic, mostly Caucasian, European populations.

Our study suggests that while insulin resistance and impaired glucose tolerance are already present, regular $\beta$-cell function is still preserved. Increasing glucose responses are compensated by equally increased insulin responses. In the presence of diabetes, however, insulin secretion is no longer sufficient to compensate for extremely high glucose levels. This is demonstrated by the trend towards a lower insulinogenic index in children and adolescents with diabetes compared with those with normal or impaired glucose tolerance. These results are in agreement with those reported by Sinha et al. (7). Adolescents with diabetes presented a significantly lower insulinogenic index than the other subjects.

The high frequencies of insulin resistance syndrome in this study reflect the scale of the childhood obesity problem and its related complications. In our study population, children and adolescents with impaired glucose tolerance presented significantly elevated total cholesterol and triglyceride levels and lower HDLcholesterol levels compared with children and adolescents with normal glucose tolerance. Furthermore, the insulin resistance index was closely correlated with hypertriglyceridemia, and the insulin sensitivity index with reduced HDL-cholesterol levels. Arslanian et al. (36) described correlations of basal insulin levels with VLDL-cholesterol and triglycerides in healthy lean children and adolescents. In this study diastolic blood pressure was negatively correlated with insulin sensitivity. In our study only the systolic blood pressure was negatively correlated with ISI.

In a recent study including obese African-American children aged 5-10 years, insulin resistance was inversely correlated with increases in blood pressure and triglycerides, but it was not correlated with LDL- or HDL-cholesterol (37).

There are associations between different features of the insulin resistance syndrome that suggest that a clustering of risk factors is present in obese children and adolescents. The presence of several signs of the insulin resistance syndrome in these children and adolescents points to the fact that they are at increased risk of developing severe complications in adulthood (38). These patients should be considered as high-risk patients who need close follow-up and intervention.

In this study no MC4R or BDNF gene mutations were detected in the 37 patients identified as being affected by impaired glucose tolerance. Thus, it seems unlikely that this particular phenotype of impaired glucose tolerance in obese children defines a subgroup with a higher prevalence of MC4R gene mutations compared with unselected early onset childhood obesity which is characterized by a prevalence of $3-5 \%$ MC4R gene mutations. At the same time these results exclude mutations in the BDNF gene as a significant genetic contribution in the pathogenesis of this subgroup of childhood obesity. Since BDNF plays a critical role during brain development and in synaptic plasticity, mutations in the coding region would probably result in a more severe phenotype. The distribution of the only known alteration in the BDNF gene, Val66Met, is identical to that reported in a control group of a study that examined the impact of that alteration in patients with schizophrenia (39).

In summary, these data indicate that in Europe impaired glucose regulation and other signs of the insulin resistance syndrome in children and adolescents are far more common than so far believed and that they are not restricted to ethnic minority groups. Screening for impaired glucose tolerance and type 2 diabetes in severely obese children and adolescents should focus on risk groups according to ADA criteria to identify a disturbed glucose tolerance as early as possible. Consequently, lifestyle modification and therapeutic interventions should follow since this would be the most effective way of avoiding secondary complications in adulthood. The use of genetic screening for early detection of obese children at risk of impaired glucose tolerance, would represent one possibility for early focussed intervention. Unfortunately this genetic screening can not be based on the MC4R gene since no higher mutation prevalence rate was identified in this subgroup. Further studies to identify the genetic predisposition for impaired glucose tolerance in childhood obesity are essential.

\section{References}

1 Troiano RP, Flegal KM, Kuczmarski RJ, Campbell SM \& Johnson CL. Overweight prevalence and trends for children and adolescents. The National Health and Nutrition Examination Surveys, 1963 to 1991. Archives of Pediatric and Adolescent Medicine $19951491085-1091$.

2 Chinn S \& Rona RJ. Prevalence and trends in overweight and obesity in three cross sectional studies of British children, 1974-1994. British Medical Journal 2001322 24-26.

3 Deckelbaum RJ \& Williams CL. Childhood obesity: the health issues. Obesity Research 20019 (Suppl 4) 239S-243S.

4 Delekat D \& Kis A. Gesundheitsberichterstattung Berlin - Zur gesundheitlichen Lage von Kindern in Berlin, pp 51-66. Berlin, Senatsverwaltung für Arbeit, Soziales und Frauen 2001. 
5 Rosenbloom AL, Joe JR, Young RS \& Winter WE. Emerging epidemic of type 2 diabetes in youth. Diabetes Care 199922 345-354.

6 Fagot-Campagna A. Emergence of type 2 diabetes mellitus in children: epidemiological evidence. Journal of Pediatric Endocrinology and Metabolism 2000 13 1395-1402.

7 Sinha R, Fisch G, Teague B, Tamborlane WV, Banyas B, Allen K. Savoye M, Rieger V, Taksali S, Barbetta G, Sherwin RS \& Caprio S. Prevalence of impaired glucose tolerance among children and adolescents with marked obesity. New England Journal of Medicine $2002346802-810$.

8 Invitti C, Guzzaloni G, Gilardini L, Morabito F \& Viberti G. Prevalence and concomitants of glucose intolerance in European obese children and adolescents. Diabetes Care 200326 118-124.

9 Drake AJ, Smith A, Betts PR, Crowne EC \& Shield JP. Type two diabetes in obese white children. Archives of Diseases in Childhood $200286207-208$.

10 Polonsky KS, Sturis J \& Bell GI. Seminars in Medicine of the Beth Israel Hospital, Boston. Non-insulin-dependent diabetes mellitus - a genetically programmed failure of the beta cell to compensate for insulin resistance. New England Journal of Medicine 1996334 777-783.

11 Haffner SM, Stern MP, Hazuda HP, Mitchell BD \& Patterson JK. Cardiovascular risk factors in confirmed prediabetic individuals. Does the clock for coronary heart disease start ticking before the onset of clinical diabetes? Journal of the American Medical Association $19902632893-2898$.

12 Tuomilehto J, Lindstrom J, Eriksson JG, Valle TT, Hamalainen H, Ilanne-Parikka P, Keinanen-Kiukaanniemi S, Laakso M, Louheranta A, Rastas M, Salminen V \& Uusitupa M. Prevention of type 2 diabetes mellitus by changes in lifestyle among subjects with impaired glucose tolerance. New England Journal of Medicine 2001344 1343-1350.

13 Farooqi IS, Keogh JM, Yeo GS, Lank EJ, Cheetham T \& O’Rahilly S. Clinical spectrum of obesity and mutations in the melanocortin 4 receptor gene. New England Journal of Medicine $2003 \mathbf{3 4 8}$ $1085-1095$

$14 \mathrm{Xu}$ B, Goulding EH, Zang K, Cepoi D, Cone RD, Jones KR, Tecott LH \& Reichardt LF. Brain-derived neurotrophic factor regulates energy balance downstream of melanocortin-4 receptor. Nature Neuroscience $20036736-742$.

15 Kernie SG, Liebl DJ \& Parada LF. BDNF regulates eating behavior and locomotor activity in mice. EMBO J 200019 $1290-1300$.

16 Rios M, Fan G, Fekete C, Kelly J, Bates B, Kuehn R, Lechan RM \& Jaenisch R. Conditional deletion of brain-derived neurotrophic factor in the postnatal brain leads to obesity and hyperactivity. Molecular Endocrinology $2001151748-1757$.

17 American Diabetes Association. Type 2 diabetes in children and adolescents. Pediatrics $2000 \mathbf{1 0 5} 671-680$.

18 Cole TJ \& Preece MA. The LMS method for constructing normalized growth standards. European Journal of Clinical Nutrition 1990 44 45-60.

19 Kromeyer-Hausschild W, Kunze D, Wabitsch M \& Geller K. Perzentile für den Body-mass-Index für das Kindes-und Jugendalter unter Heranziehung verschiedener deutscher Stichproben. Monatsschr Kinderheilkd 2001149 807-818.

20 Report of the Second Task Force on Blood Pressure Control in Children-1987. Pediatrics 198779 1-25.

21 Marshall T. Variations in patterns of pubertal changes in girls. Archives of Diseases in Childhood $1979 \mathbf{4 4} 291-303$.

22 Marshall T. Variations in patterns of pubertal changes in boys. Archives of Diseases in Childhood 197945 13-23.

23 Alberti Z. New diagnostic criteria and classification of diabetesagain? Diabetic Medicine 199815 535-536.
24 Alberti KG \& Zimmet PZ. Definition, diagnosis and classification of diabetes mellitus and its complications. Part 1: diagnosis and classification of diabetes mellitus provisional report of a WHO consultation. Diabetic Medicine 199815 539-553.

25 Matthews DR, Hosker JP, Rudenski AS, Naylor BA, Treacher DF \& Turner RC. Homeostasis model assessment: insulin resistance and beta-cell function from fasting plasma glucose and insulin concentrations in man. Diabetologia 198528 412-419.

26 Bonora E, Targher G, Alberiche M, Bonadonna RC, Saggiani F, Zenere MB, Monauni T \& Muggeo M. Homeostasis model assessment closely mirrors the glucose clamp technique in the assessment of insulin sensitivity: studies in subjects with various degrees of glucose tolerance and insulin sensitivity. Diabetes Care $20002357-63$.

27 Matsuda M \& DeFronzo RA. Insulin sensitivity indices obtained from oral glucose tolerance testing: comparison with the euglycemic insulin clamp. Diabetes Care 199922 1462-1470.

28 Phillips C. Hales CN \& Osmond C. Understanding oral glucose tolerance: comparison of glucose or insulin measurements during the oral glucose tolerance test with specific measurements of insulin resitance and secretion. Diabetic Medicine 199311 286-292.

29 Efendic L. Aspects of the pathogenesis of type 2 diabetes. Endocrine Reviews 19845 395-410.

30 Haffner SM, Miettinen H, Gaskill SP \& Stern MP. Decreased insulin secretion and increased insulin resistance are independently related to the 7-year risk of NIDDM in Mexican-Americans. Diabetes $1995 \mathbf{4 4} 1386-1391$.

31 Report of the Expert Committee on the Diagnosis and Classification of Diabetes Mellitus, Diabetes Care $1997201183-1197$.

32 Reaven GM. Role of insulin resistance in human disease. Diabetes $1988371595-1607$.

33 Glucose tolerance and mortality: comparison of WHO and American Diabetes Association diagnostic criteria. The DECODE study group. European Diabetes Epidemiology Group. Diabetes Epidemiology: Collaborative analysis of diagnostic criteria in Europe. Lancet $1999354617-621$.

34 Fagot-Campagna A, Saaddine JB \& Engelgau MM. Is testing children for type 2 diabetes a lost battle? Diabetes Care 200023 1442-1443.

35 Ehtisham S, Barrett TG \& Shaw NJ. Type 2 diabetes mellitus in UK children-an emerging problem. Diabetic Medicine 200017 867-871.

36 Arslanian S \& Suprasongsin C. Insulin sensitivity, lipids, and body composition in childhood: is "syndrome X" present? Journal of Clinical Endocrinology and Metabolism 199681 1058-1062.

37 Young-Hyman D, Schlundt DG, Herman L, De Luca F \& Counts D. Evaluation of insulin resistance syndrome in 5- to 10-year old overweight/obese African-American Children. Diabetes Care 200124 1359-1364.

38 Freedman DS, Khan LK, Dietz WH, Srinivasan SR \& Berenson GS. Relationship of childhood obesity to coronary heart disease risk factors in adulthood: the Bogalusa Heart Study. Pediatrics 2001 $108712-718$.

39 Egan MF, Kojima M, Callicott JH, Goldberg TE, Kolachana BS, Bertolino A, Zaitsev E, Gold B, Goldman D, Dean M, Lu B \& Weinberger DR. The BDNF val66met polymorphism affects activity-dependent secretion of BDNF and human memory and hippocampal function. Cell 2003112 257-269.

Received 21 January 2004

Accepted 3 May 2004 